\title{
Normal myelopoiesis but abnormal T lymphocyte responses in vitamin $D$ receptor knockout mice
}

\author{
James O'Kelly, ${ }^{1}$ Junichi Hisatake, ${ }^{1}$ Yasako Hisatake, ${ }^{1}$ June Bishop, ${ }^{2}$ Anthony Norman, ${ }^{2}$ \\ and H. Phillip Koeffler ${ }^{1}$ \\ ${ }^{1}$ Division of Hematology/Oncology, Cedars-Sinai Medical Center, University of California Los Angeles School of Medicine, \\ Los Angeles, California, USA \\ ${ }^{2}$ Department of Biochemistry, University of California Riverside, Riverside, California, USA
}

Address correspondence to: James O'Kelly, Division of Hematology/Oncology, Cedars-Sinai Medical Center, University of California Los Angeles School of Medicine, 8700 Beverly Boulevard, Los Angeles, California 90048, USA. Phone: (310) 423-7733; Fax: (310) 423-0443; E-mail: okellyj@cshs.org.

Received for publication January 31, 2001, and accepted in revised form March 11, 2002.

\begin{abstract}
The vitamin $\mathrm{D}$ receptor (VDR) is a transcription factor that mediates the actions of its ligand, 1,25-dihydroxyvitamin $\mathrm{D}_{3}\left[1,25(\mathrm{OH})_{2} \mathrm{D}_{3}\right]$, which can promote monocyte/macrophage differentiation and inhibit proliferation and cytokine production by activated T lymphocytes. In this study, VDR knockout (KO) mice were used to investigate the possible role of VDR in hematopoiesis. The relative number of red and white peripheral blood cells and the percentage of bone marrow macrophages did not differ between VDR KO and wild-type mice. 12-O-tetradecanoylphorbol-13acetate, but not $1,25(\mathrm{OH})_{2} \mathrm{D}_{3}$, induced differentiation of bone marrow-committed myeloid stem cells from VDR KO mice to monocytes/macrophages. Production of IL-18, a Th1-promoting cytokine, was reduced in macrophages from these mice. Antigen-stimulated spleen cells from VDR KO mice showed an impaired Th 1 cell response and had decreased expression of STAT4, a Th1 cell transcription factor. These results demonstrate the absolute requirement of VDR for $1,25(\mathrm{OH})_{2} \mathrm{D}_{3^{-}}$ induced monocyte/macrophage differentiation but show that monocyte/macrophage differentiation can occur in the absence of this receptor. The observed reduction in Th1 population in these mutant mice may be explained by a loss of macrophage IL-18 production or a suppression of STAT 4 expression by activated splenocytes.
\end{abstract}

J. Clin. Invest. 109:1091-1099 (2002). DOI:10.1172/JCI200212392.

\section{Introduction}

The genomic actions of 1,25-dihydroxyvitamin $\mathrm{D}_{3}$ $\left[1,25(\mathrm{OH})_{2} \mathrm{D}_{3}\right]$ are mediated by the intracellular vitamin $\mathrm{D}$ receptor (VDR), a ligand-activated transcription factor belonging to a large family of nuclear receptors (1). VDR forms a heterodimer with the retinoid $\mathrm{X}$ receptor; this complex regulates expression of target genes by binding to vitamin $\mathrm{D}$-responsive elements in their promoter regions (2). The classical actions of vitamin $\mathrm{D}$ are those concerned with the regulation of calcium homeostasis; however, the widespread distribution of VDR in many cell types clearly shows that the vitamin $\mathrm{D}$ endocrine system is involved in the regulation of many cell types and cell lineages (3). Studies using VDR knockout (KO) mice have demonstrated that after weaning, VDR plays an essential role in growth, bone formation, uterine maturation, hair production, and estrogen metabolism (4-7).

Expression of VDR has been detected in various normal and leukemic hematopoietic cells, including macrophages and activated $T$ lymphocytes $(8,9)$. Evidence from other studies strongly suggests a role for VDR in hematopoiesis: Normal and leukemic myeloid progenitor cells can be induced to differentiate into monocytes and macrophages by $1,25(\mathrm{OH})_{2} \mathrm{D}_{3}(10-14)$; activated normal macrophages are able to synthesize $1,25(\mathrm{OH})_{2} \mathrm{D}_{3}(15,16)$; and $1,25(\mathrm{OH})_{2} \mathrm{D}_{3}$ inhibits proliferation of activated $\mathrm{T}$ lymphocytes (17) and suppresses their synthesis of GM-CSF (18), IFN- $\gamma(19)$, and IL-2 $(17,20)$.

The actions of $1,25(\mathrm{OH})_{2} \mathrm{D}_{3}$ on the immune system are thought to be targeted primarily at Th cells $(21,22)$, which can be divided into two subsets that direct divergent immune responses through the secretion of distinct cytokine profiles $(23,24)$. Th1 cells produce IL-2 and IFN- $\gamma$ and regulate cell-mediated immunity. In contrast, Th2 cells produce IL-4, IL-6, and IL-10, which generate a humoral immune response by enhancing $B$ cell activation and differentiation. The observation that $1,25(\mathrm{OH})_{2} \mathrm{D}_{3}$ inhibits the Th1-specific cytokines IL-2 and IFN- $\gamma$, but has little effect on Th2-specific IL-4 production, has led to the hypothesis that its immunosuppressive properties are achieved by regulation of Th1 cell activity (21). In support of this theory, production by activated macrophages of IL-12, which promotes a Th1 response, is inhibited by $1,25(\mathrm{OH})_{2} \mathrm{D}_{3}(25)$.

Myeloid and lymphoid cells from patients with vitamin D-dependent rickets type II, in which VDR is functionally defective, are unable to respond to $1,25(\mathrm{OH})_{2} \mathrm{D}_{3}$ $(26,27)$. Therefore, normal expression of VDR appears to be a requirement for the wide-ranging effects of 
$1,25(\mathrm{OH})_{2} \mathrm{D}_{3}$ on hematopoietic cells. The VDR KO mouse provides an excellent model with which to study the importance of VDR in the hematopoietic system. In this study, we explored the consequences of deletion of the VDR on myelopoiesis by examining cell fractions present in the peripheral blood and by comparing the differentiation and function of bone marrow-derived macrophages. Concerning the immune system, activated splenic T cells were demonstrated to be defective in VDR KO mice, revealing a potentially new role for VDR in the regulation of the immune response.

\section{Methods}

Animals and cells. VDR KO mice were generated as described previously (4) and bred under sterile conditions in the animal facility at the Cedars-Sinai Medical Center. Genotypes were determined by Southern blot analysis of genomic DNA from tail clippings, which was digested with the restriction enzyme PvuII. For experiments using VDR KO mice, their wild-type (WT) littermates were used as controls. Mice were killed by cervical neck dislocation. Peripheral blood was obtained by bleeding from the orbital sinus, and bone marrow was flushed out of isolated femurs with Alpha Minimum Essential Medium ( $\alpha$-MEM; Gibco BRL, Grand Island, New York, USA) including 10\% FCS using a 26-gauge needle. Isolated spleens were injected with DMEM (Gibco BRL) plus 10\% FCS and crushed with forceps to release cells. Mononuclear cells from bone marrow or spleen were separated by FicollHypaque density centrifugation (Amersham Pharmacia, Uppsala, Sweden).

Colony-forming assay. Resuspended mononuclear bone marrow cells $\left(2 \times 10^{4}\right.$ cells $\left./ \mathrm{ml}\right)$ and growth factors were added 1:10 to methylcellulose medium M3234 (StemCell Technologies Inc., Vancouver, British Columbia, Canada) to yield a final concentration of $1 \%$ methylcellulose, $30 \%$ FCS, $1 \%$ BSA, $10^{-4} \mathrm{M}$ mercaptoethanol, and $2 \mathrm{mM}$ L-glutamine. Cytokines were used at the concentrations indicated later in this section. 12-O-tetradecanoylphorbol-13-acetate (TPA) and $1,25(\mathrm{OH})_{2} \mathrm{D}_{3}$ were dissolved in ethanol, diluted in media, and used at the concentrations indicated later in this section. Cells were plated in six-well plates in a volume of $1 \mathrm{ml}$ and incubated at $37^{\circ} \mathrm{C}$ in a humidified atmosphere containing $5 \% \mathrm{CO}_{2}$. Colonies were counted after 2 weeks. Colony type was established by morphology, and to ensure accurate determination, representative colonies were picked from the plates, centrifuged onto slides, and stained with Wright-Giemsa stain.

Bone marrow macrophage cultures. Bone marrow mononuclear cells were cultured in the presence of GM-CSF (10 ng/ml), IL-3 (10 ng/ml), and mercaptoethanol $\left(10^{-4} \mathrm{M}\right)$ for 10 days to induce macrophage differentiation. Adherent macrophages were detached by incubation with $50 \mathrm{mM}$ EDTA in PBS for 10 minutes at $4{ }^{\circ} \mathrm{C}$. The cells were counted, and $10^{6}$ cells in $1 \mathrm{ml}$ media were plated in 24 -well plates, either with or without LPS $(20 \mu \mathrm{g} / \mathrm{ml})$ and
$1,25(\mathrm{OH})_{2} \mathrm{D}_{3}\left(10^{-7} \mathrm{M}\right)$. Cells and culture supernatants were harvested after incubation for 24 hours.

Spleen cell cultures. Twenty-four-well culture plates were coated with anti-CD3 antibody $(10 \mu \mathrm{g} / \mathrm{ml}$; PharMingen, San Diego, California, USA) in PBS, either overnight at $4^{\circ} \mathrm{C}$ or for 2 hours at $37^{\circ} \mathrm{C}$. Cells $\left(10^{6}\right.$ cells $\left./ \mathrm{ml}\right)$ were incubated with anti-CD28 antibody $(2 \mu \mathrm{g} / \mathrm{ml}$; PharMingen) in DMEM plus $10 \%$ FCS and antibiotics at $37^{\circ} \mathrm{C}$ with $5 \% \mathrm{CO}_{2}$. To stimulate Th1 cell differentiation, IL-12 (100 ng/ml; PharMingen) was added; to stimulate Th2 2 cell differentiation, anti-IL- 12 antibody $(50 \mu \mathrm{g} / \mathrm{ml}$; PharMingen) or IL-4 (10 ng/ml; PharMingen) was added at the start of culture. Cytokine production was assessed using commercial ELISA kits (R\&D Systems Inc., Minneapolis, Minnesota, USA). Cells were grown as described above by adding $1 \mathrm{ml}$ of cell culture to 24well plates and incubating for 3-5 days, and culture supernatants were stored at $-20^{\circ} \mathrm{C}$ until analysis was performed. Proliferation was determined by incubating cells $(200 \mu \mathrm{l})$ with plate-bound anti-CD3 and soluble anti-CD28 for 3 days in triplicate wells of 96-well plates. $\left[{ }^{3} \mathrm{H}\right]$ thymidine $(0.25 \mu \mathrm{Ci})$ was added to each well for the last 14 hours of culture. Cells were harvested onto filters, which were assayed for $\left[{ }^{3} \mathrm{H}\right]$ thymidine content using a plate reader.

Western blot analysis and immunoprecipitation. Cells were washed twice in ice-cold PBS and lysed in radioimmunoprecipitation assay (RIPA) buffer $(150 \mathrm{mmol} / \mathrm{l}$ $\mathrm{NaCl}, 50 \mathrm{mmol} / \mathrm{l}$ Tris- $\mathrm{HCl}$ [pH 8.0], 0.5\% deoxycholate, $1 \% \mathrm{NP}-40$, and $1 \%$ SDS) containing protease inhibitors over a period of 30 minutes on ice. After centrifugation at $15,000 \mathrm{~g}$ for 20 minutes at $4^{\circ} \mathrm{C}$, the supernatant was collected. Protein concentrations were determined using an assay kit according to the manufacturer's instructions (Bio-Rad Laboratories Inc., Hercules, California, USA). Lysates were separated by SDS-PAGE on a 4-15\% linear gradient Ready Gel (Bio-Rad Laboratories Inc.) and transferred to an Immobilon-P membrane (Millipore Corp., Bedford, Massachusetts, USA). Lysates were then probed with $1 \mu \mathrm{g} / \mathrm{ml}$ anti-p27Kip1 rabbit polyclonal antibody, anti-actin goat polyclonal antibody, mouse monoclonal antibody against nuclear factor of activated $T$ cells (NFATc), rabbit polyclonal antibody against signal transducer and activator of transcription 4 (STAT4) (all from Santa Cruz Biotechnology Inc., Santa Cruz, California, USA), and anti-p21 Waf1/Cip1 murine monoclonal antibody (Oncogene Science Inc., Uniondale, New York, USA). Bound antibody was detected using horseradish peroxidase-conjugated secondary antibodies and developed using the enhanced chemiluminescence (ECL) substrate from Amersham Corp. (Arlington Heights, Illinois, USA).

For immunoprecipitation, cell lysates were incubated with $50 \mu \mathrm{l}$ of anti-fyn goat polyclonal antibody on ice for 1 hour. The antibody-antigen complex was precipitated with $50 \mu \mathrm{l}$ of protein A (CalbiochemNovabiochem Corp., San Diego, California, USA) on ice for 30 minutes, washed twice, resuspended in loading buffer, and subjected to SDS-PAGE as 
Table 1

Peripheral blood analysis and bone marrow macrophage counts of VDR WT and KO mice

\begin{tabular}{lcc} 
& WT mice & VDR KO mice \\
Peripheral blood & & \\
WBCs $\left(10^{3} / \mathrm{mm}^{3}\right)$ & $7.0 \pm 0.3$ & $6.4 \pm 0.7$ \\
RBCs $\left(10^{3} / \mathrm{mm}^{3}\right)$ & $9.1 \pm 0.2$ & $9.1 \pm 0.5$ \\
Hemoglobin $(\mathrm{g} / \mathrm{dl})$ & $15.1 \pm 1.3$ & $13.9 \pm 1.0$ \\
Hematocrit $(\%)$ & $43.7 \pm 0.7$ & $43.1 \pm 2.5$ \\
Lymphocytes $(\%)$ & $82.3 \pm 12.3$ & $84.3 \pm 12.1$ \\
Granulocytes $(\%)$ & $8.3 \pm 5.4$ & $7.0 \pm 5.7$ \\
Bone marrow & & \\
Macrophages (\%) & $6.5 \pm 1.0$ & $7.6 \pm 1.6$ \\
\hline
\end{tabular}

Peripheral blood was drawn from mice at the time of their sacrifice (4-7 weeks of age), and bone marrow macrophages were counted by $\alpha$-naphthyl esterase staining of bone marrow cytopreparations. Data are presented as mean $\pm S D$ of measurements from three mice using light microscopy.

described above. The membrane was probed with 1 $\mu \mathrm{g} / \mathrm{ml}$ anti-tyrosine kinase antibody and detected using the ECL system.

PCR analysis. A twenty-microliter volume of $\mathrm{cDNA}$ was prepared from $1 \mu \mathrm{g}$ of Trizol-extracted RNA. The specific primers were as follows: IL-4, 5'-GAATGTACCAGGAGCCATATC- $3^{\prime}$ and $5^{\prime}$-CTCAGTACTACGAGTAATCCA-3'; IFN- $\gamma, 5^{\prime}$-AACGCTACACACTGCATCTTGG-3' and $5^{\prime}$-GACTTCAAAGAGTCTGAGG-3'; IL-2, $5^{\prime}$-GAGTCAAATCCAGAACATGCC- $3^{\prime}$ and $5^{\prime}$-TCCACTTCAAGCTCTACAG- $3^{\prime}$; GM-CSF, $5^{\prime}$-GCTACCACCTATGCGGATTT- $3^{\prime}$ and $5^{\prime}$-CTGTGCCACATCTCTTGGTC-3'; 18S, 5'-AAACGGCTACCACATCCAAG- ${ }^{\prime}$ and $5^{\prime}$-CCTCCAATGGATCCTCGTTA-3'. Cycling was done with an initial denaturation step of 9 minutes, followed by 30 seconds at $94^{\circ} \mathrm{C}, 30$ seconds at annealing temperature $\left(50^{\circ} \mathrm{C}\right.$ for cytokines and $55^{\circ} \mathrm{C}$ for $18 \mathrm{~S}$ ), 2 minutes at $72^{\circ} \mathrm{C}$, and a final elongation step of 7 minutes at $72^{\circ} \mathrm{C}$. The cycle number was 22 for $18 \mathrm{~S}$ and 30 for cytokines. PCR product was separated on a $2 \%$ agarose gel, stained with ethidium bromide, and photographed.

\section{Results}

Hematopoiesis. Analysis of peripheral blood revealed no differences in the numbers or percentages of red and white cells between VDR KO and WT mice (Table 1). $1,25(\mathrm{OH})_{2} \mathrm{D}_{3}$, acting through the VDR, has previously been shown to stimulate the differentiation of normal bone marrow cells into monocytes/macrophages (10).

\section{Figure 1}

Colony formation by mononuclear bone marrow cells from VDR KO and WT mice. Mononuclear cells were obtained from femoral bone marrow plugs and grown in methylcellulose media containing cytokines and various concentrations of $1,25(\mathrm{OH})_{2} \mathrm{D}_{3}$. Colonies were counted on day 10 of culture. Control cultures from WT and KO mice contained a mean of $96 \pm 37$ and $98 \pm 15$ myeloid colonies, respectively. Numbers represent the mean \pm SD of three experiments performed on triplicate wells using cells from three KO and three WT mice. Triangles, granulocyte colonies; circles, macrophage colonies; squares, mixed granulocyte/macrophage colonies.
The percentages of macrophages in the VDR KO bone marrow and monocytes in the peripheral blood were both the same as those found in WT mice (Table 1).

Myeloid differentiation. We used a soft-gel clonogenic assay to determine the number and percentage of granulocyte, macrophage, and granulocyte/macrophage mixed colonies derived from committed myeloid stem cells from the mononuclear bone marrow cells. Addition of $1,25(\mathrm{OH})_{2} \mathrm{D}_{3}$ to these soft-gel cultures markedly altered the differentiation of committed myeloid stem cells from WT mice, but not those from VDR KO mice (Figure 1). For example, in the WT mice, $1,25(\mathrm{OH})_{2} \mathrm{D}_{3}\left(10^{-7} \mathrm{M}\right)$ dramatically increased the percentage of macrophage colonies [control dishes, $28 \% \pm 3 \% ; 1,25(\mathrm{OH})_{2} \mathrm{D}_{3}$-containing dishes, $67 \% \pm 9 \%$; mean $\pm \mathrm{SD}$ ] and decreased the percentage of mixed colonies [control dishes, $55 \% \pm 8 \% ; 1,25(\mathrm{OH})_{2} \mathrm{D}_{3}$-containing dishes, $30 \% \pm 1 \%$; mean $\pm \mathrm{SD}$ ] (Figure 1 ). By contrast, in the $\mathrm{KO}$ mice, $1,25(\mathrm{OH})_{2} \mathrm{D}_{3}\left(10^{-7} \mathrm{M}\right)$ did not affect the percentage of macrophage colonies [control dishes, $25 \% \pm 9 \% ; 1,25(\mathrm{OH})_{2} \mathrm{D}_{3}$-containing dishes, $23 \% \pm 5 \%$ ] or the percentage of mixed colonies [control dishes, $61 \% \pm 9 \% ; 1,25(\mathrm{OH})_{2} \mathrm{D}_{3}$-containing dishes, $66 \% \pm 9 \%$; mean $\pm \mathrm{SD}$ ] (Figure 1). One possible explanation for these observations is that bone marrow cells from VDR KO mice were unable to respond to a differentiation stimulus. Therefore, cultures were treated with TPA, as this stimulator of phosphokinase $C$ is known to induce macrophage colony formation (28). TPA $\left(5 \times 10^{-10} \mathrm{M}\right)$ increased the proportion of macrophage colonies from bone marrow of both WT and KO
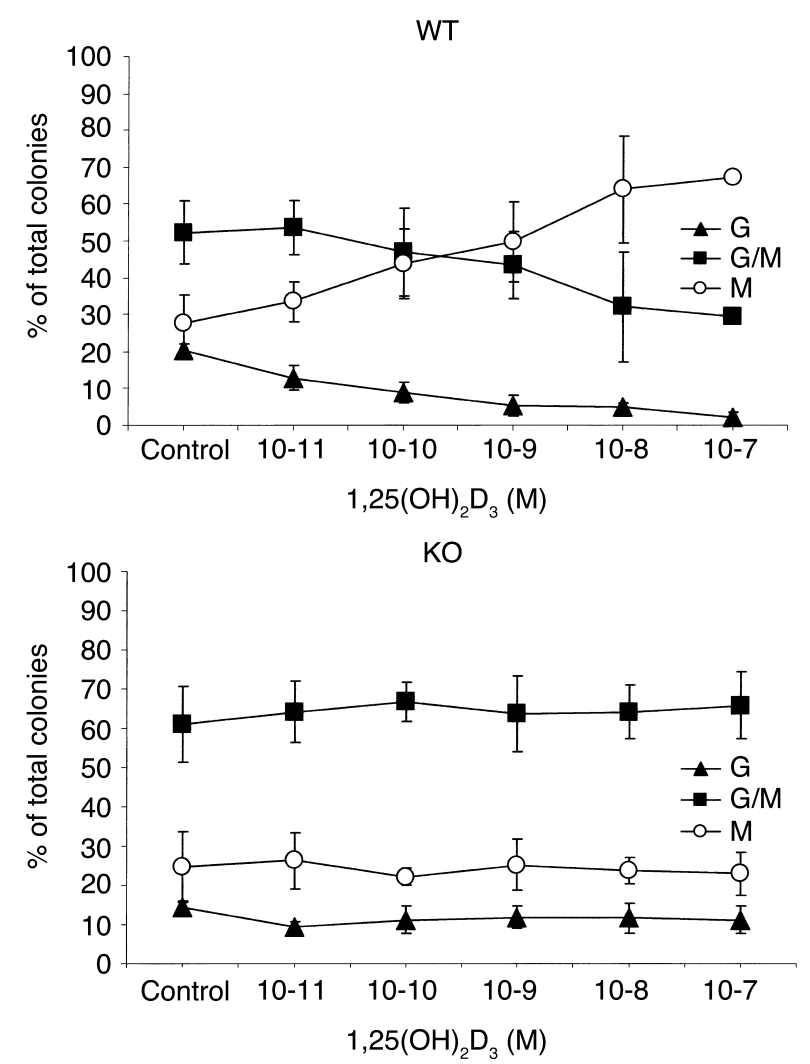
Table 2

Effect of TPA on colony formation by bone marrow cells

\begin{tabular}{|c|c|c|c|c|c|c|}
\hline \multirow[b]{3}{*}{ TPA } & \multicolumn{6}{|c|}{ Colony formation (\% of total colonies) } \\
\hline & \multicolumn{3}{|c|}{ WT mice } & \multicolumn{3}{|c|}{ KO mice } \\
\hline & Granulocyte & Mixed & Macrophage & Granulocyte & Mixed & Macrophage \\
\hline Control & $20 \pm 4$ & $58 \pm 2$ & $22 \pm 1$ & $16 \pm 4$ & $64 \pm 5$ & $23 \pm 3$ \\
\hline $1 \times 10^{-10} \mathrm{M}$ & $4 \pm 2$ & $61 \pm 2$ & $35 \pm 7$ & $4 \pm 1$ & $55 \pm 1$ & $48 \pm 7$ \\
\hline $5 \times 10^{-10} \mathrm{M}$ & $4 \pm 1$ & $53 \pm 4$ & $43 \pm 3$ & $3 \pm 0$ & $51 \pm 1$ & $46 \pm 1$ \\
\hline
\end{tabular}

Mononuclear cells were obtained from femoral bone marrow and grown in methylcellulose media containing cytokines and various concentrations of TPA Colonies were counted on day 10 of culture. Control cultures from WT and KO mice contained a mean of $93 \pm 22$ and $117 \pm 15$ myeloid colonies, respectively. Numbers represent the mean \pm SD of separate experiments performed on three pairs of mice, using triplicate wells per experimental point.

mice (WT mice: control dishes, $22 \% \pm 1 \%$; TPA-containing dishes, $43 \% \pm 3 \%$ vs. KO mice: control dishes, $23 \% \pm 3 \%$; TPA-containing dishes, $46 \% \pm 1 \%$ ), indicating that differentiation along this pathway was not impaired (Table 2).

To further characterize the effect of VDR deletion on the status of myeloid progenitors, we analyzed the ability of these progenitors to respond to the myeloid-specific cytokines GM-CSF, G-CSF, and M-CSF, and the multilineage cytokine IL-3 (Table 3). The response of VDR KO bone marrow cells to cytokine stimulation was the same as the response of WT cells. Bone marrow cells from VDR KO mice produced more colonies on average than bone marrow cells from WT mice when cultured with G-CSF, and fewer colonies than bone marrow cells from WT mice when cultured with M-CSF, but these differences were not statistically significant (G-CSF, $P>0.3$; M-CSF, $P>0.6$ ).

The molecular mechanisms governing monocyte/ macrophage differentiation were examined further to investigate the role of VDR in this process. The cyclindependent kinase inhibitors $\mathrm{p} 21^{\text {Waf1/Cip1 }}$ and $\mathrm{p} 27^{\mathrm{Kip} 1}$ have been shown to be important in vitamin $\mathrm{D}_{3}$-induced monocyte differentiation, and their overexpression in U937 cells stimulates expression of the monocyte phenotype (29). Bone marrow macrophages were grown in liquid culture with GM-CSF and IL-3, and protein was extracted at 6 hours and 48 hours. Bone marrow cells from VDR KO mice responded to cytokine stimulation in the same manner as did those from WT mice (Figure 2). Protein levels of $\mathrm{p} 21^{\text {Wafl/Cip1 }}$ and $\mathrm{p} 27^{\text {Kip } 1}$ decreased during the 72-hour stimulation period. Conversely, expression of cyclins D1 and D2 was induced by cytokine stimulation in both VDR KO and WT bone marrow cells.

To determine the effect of the absence of VDR on macrophage function, we examined cytokine production by mature macrophages. Bone marrow macrophages were stimulated with LPS, and the cytokine content of the media was determined. IL-18 is a recently described cytokine produced by macrophages; data suggest that it may be involved in regulating the immune response $(30,31)$. Interestingly, unstimulated macrophages from VDR KO mice produced significantly less IL-18 $(P<0.01)$ than did those from WT mice (Figure 3). Furthermore, IL-18 levels in LPS-stimulated macrophages from VDR KO mice were signifi- cantly less $(P<0.05)$ than in macrophages from WT mice. $1,25(\mathrm{OH})_{2} \mathrm{D}_{3}$ has been reported to inhibit IL-12 secretion and gene expression by macrophages (25). IL-12 production by stimulated and unstimulated macrophages from the VDR KO mice and the WT mice was the same (Figure 3).

Splenocytes. No differences in the proportions of $\mathrm{T}$ and $B$ lymphocytes in the spleen, thymus, and lymph nodes were observed between the VDR KO and WT mice (data not shown), in agreement with previous studies (4). Mononuclear spleen cell cultures of VDR KO and WT mice stimulated with plate-bound CD3 and soluble CD28 secreted a different cytokine profile, as determined by ELISA (Figure 4a). Spleen cells from WT mice produced fourfold greater levels of IFN- $\gamma$ than did those from VDR KO mice, and secreted slightly higher levels of IL-2 (Figure 4a). In contrast, IL-4 production was reduced in splenocytes from WT mice compared with VDR KO cultures (Figure 4a). Spleen cell numbers were the same at the end of the culture period, indicating that differences observed in cytokine production were not due to cell death. To examine events occurring at the transcriptional level, we analyzed expression of IFN- $\gamma$ mRNA in these cells by RT-PCR (Figure 4b). In contrast with the ELISA results, mRNA expression was not different in antibody-stimulated VDR KO spleen

\section{Table 3}

Effect of cytokines on colony formation by bone marrow cells

\begin{tabular}{lccc}
\hline & & \multicolumn{2}{c}{ Number of colonies } \\
& CSF $(\mathrm{ng} / \mathrm{ml})$ & WT mice & KO mice \\
Control & 10 & 0 & 0 \\
GM-CSF & 10 & $115 \pm 23$ & $116 \pm 27$ \\
& 100 & $132 \pm 30$ & $134 \pm 29$ \\
GM-CSF + IL-3 & 10 & $149 \pm 29$ & $172 \pm 49$ \\
G-CSF & 100 & $150 \pm 33$ & $164 \pm 45$ \\
& 10 & $66 \pm 28$ & $100 \pm 66$ \\
G-CSF + IL-3 & 100 & $131 \pm 24$ & $164 \pm 41$ \\
& 10 & $167 \pm 38$ & $160 \pm 41$ \\
M-CSF & 100 & $206 \pm 57$ & $187 \pm 32$ \\
& 100 & $216 \pm 51$ & $171 \pm 41$ \\
& & & $180 \pm 44$
\end{tabular}

Mononuclear cells were obtained from femoral bone marrow and grown in methylcellulose media containing cytokines. When present, IL-3 was at a concentration of $10 \mathrm{ng} / \mathrm{ml}$. Colonies were counted on day 10 of culture. Numbers represent the mean of two experiments performed on pairs of mice in triplicate wells per experimental point. 


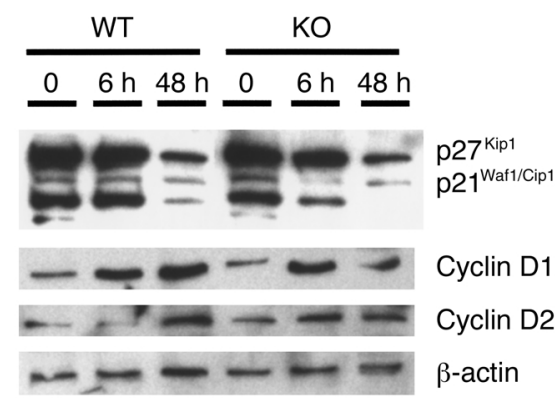

Figure 2

Expression of $\mathrm{p} 21^{\mathrm{Waf1} / \mathrm{Cip} 1}$ and $\mathrm{p} 27^{\mathrm{Kip} 1}$ by bone marrow-derived macrophages from VDR WT and KO mice. Mononuclear bone marrow cells were cultured with $10 \mathrm{ng} / \mathrm{ml} \mathrm{IL-3}$ and $10 \mathrm{ng} / \mathrm{ml} \mathrm{GM-CSF}$ to induce macrophage differentiation. Cells were harvested at time 0 , 6 hours, and 48 hours, and analyzed by Western blotting

cells compared with WT cells. These data suggest that VDR expression is required for the development of a normal Th1 cell response.

Differentiation of Th cells toward a Th1 or Th2 phenotype can be achieved by costimulation with a polarizing cytokine or antibody. Antigen-stimulated splenocyte cultures were supplemented with IL-12 to induce Th1 cell differentiation, or with either IL-4 or anti-IL-12 antibody to induce Th2 cell differentiation. Exogenous IL-12 increased the amount of IFN- $\gamma$ secreted by Th1 cells, but production by VDR KO cells remained below normal levels (Figure 5a). Production of IL- 4 by Th 2 cells was also increased by addition of anti-IL-12 compared with antigen stimulation alone (Figure $5 \mathrm{~b}$ ); and although slightly less IL-4 production was observed in WT cultures, the difference was not statistically significant.

An altered proliferative response to polarizing cytokines could contribute to the differences in the cytokine levels. Splenic cellular proliferation over 3 days showed a dose-dependent response to IL-12 and IL-4, as determined by $\left[{ }^{3} \mathrm{H}\right]$ thymidine incorporation (Figure 6). Proliferation of VDR KO splenocytes in response to IL-12 was half that of WT cells (Figure 6a), but was up to 1.4-fold greater than that of WT cells in response to IL-4 (Figure 6b). Cell cycl analysis of splenocytes stimulated with $100 \mathrm{ng} / \mathrm{ml} \mathrm{IL-12}$ for 3 days revealed that a smaller proportion of the VDR KO cells were in the G1 phase (WT, $68 \% \pm 9 \%$; KO, $53 \% \pm 5 \%$; mean $\pm \mathrm{SD}$ ). These data suggest that the decreased levels of IFN- $\gamma$ and increased levels of IL-4 produced by activated VDR KO spleen cells in culture are due at least partially to reduced Th1 cells and increased Th2 proliferation.

We used Western analysis to determine expression of the transcription factors STAT4 and NFATc, which are involved in directing the differentiation of naive Th cells toward Th1 cells or Th2 cells, respectively. Decreased expression of STAT4 was observed in antibody-stimulated spleen cells from VDR KO mice compared with those from WT mice (Figure 7). Spleen cells from KO mice given additional stimulation with IL-12 or IL-4 also expressed reduced levels of STAT4 compared with those from WT mice. In contrast, levels of NFATc were the same in activated splenocytes from VDR KO and WT mice (Figure 7). We tested the expression of the NFATc target genes GM-CSF and IL-2 by RT-PCR. No difference was found in the expression of GM-CSF or IL-2 in activated splenocytes from VDR KO and WT mice (Figure 7). It is possible that the T cells lacking VDR were unable to properly transduce the signal from the $\mathrm{T}$ cell receptor in response to $\mathrm{CD} 3$ ligation. Therefore, we examined the phosphorylation status of fyn, whose expression and activation are increased in $\mathrm{T}$ cells following anti-CD3 stimulation (32). Protein lysates from stimulated spleen cells were immunoprecipitated with an anti-fyn antibody, and phosphorylation of fyn was detected by Western blot using a tyrosine kinase-specific antibody. We could not detect any differences in the tyrosine phosphorylation of fyn between the VDR KO and WT splenocytes, regardless of the stimulus received (Figure 7).

\section{Discussion}

The seco-steroid hormone $1,25(\mathrm{OH})_{2} \mathrm{D}_{3}$ is widely believed to play a role in normal hematopoiesis by enhancing the differentiation of monocytes/macrophages and inhibiting the proliferation and cytokine production of activated lymphocytes $(21,33,34)$. These
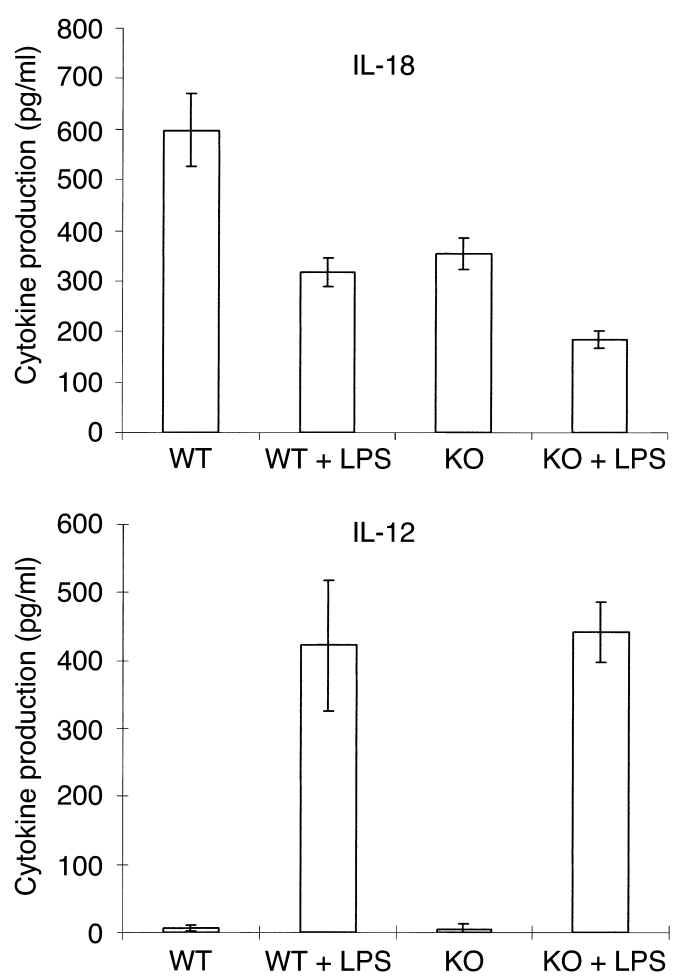

Figure 3

Cytokine production by bone marrow macrophages. Mononuclear bone marrow cells were cultured for 10 days with $10 \mathrm{ng} / \mathrm{ml} \mathrm{IL-3}$ and GM-CSF to induce macrophage differentiation. Macrophages $\left(10^{6}\right)$ in $1 \mathrm{ml}$ media were incubated for 24 hours either with or without 20 $\mu \mathrm{g} / \mathrm{ml} \mathrm{LPS}$, and conditioned media were analyzed by ELISA. The results represent the mean \pm SD of three experiments performed on triplicate wells using cells from three KO and three WT mice. 


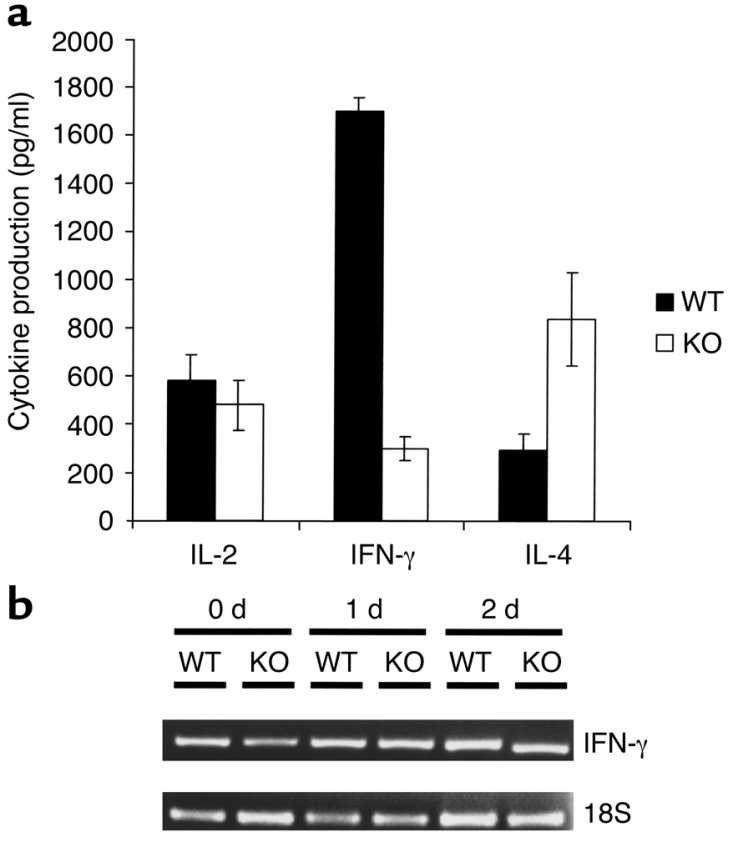

actions of $1,25(\mathrm{OH})_{2} \mathrm{D}_{3}$ are thought to be mediated through the VDR, which interacts with a broad range of genes to regulate their expression (35). We used a colony assay that allows committed myeloid stem cells to differentiate to either granulocytes or monocytes, or a combination of both. Committed myeloid stem cells from VDR KO mice and WT mice were equally responsive to all combinations of the tested cytokines, as determined by the number of colonies formed in culture. Very low concentrations of $1,25(\mathrm{OH})_{2} \mathrm{D}_{3}\left(10^{-10}\right.$ to $\left.10^{-9} \mathrm{M}\right)$ added to the culture selectively induced WT myeloid stem cells to differentiate into macrophages. This is consistent with our previous observations (10). In stark contrast, these committed stem cells from the VDR KO bone marrow did not preferentially differentiate into macrophages in the presence of increasing concentrations of $1,25(\mathrm{OH})_{2} \mathrm{D}_{3}$, and even $10^{-7} \mathrm{M} 1,25(\mathrm{OH})_{2} \mathrm{D}_{3}$ was unable to increase the percentage of stem cells differentiating into macrophage colonies. Nevertheless, the myeloid stem cells of the VDR KO mice were able, in soft agar, to differentiate into macrophages with the addition of another macrophage inducer, TPA. $1,25(\mathrm{OH})_{2} \mathrm{D}_{3}$ induces committed myeloid stem cells to differentiate into monocytes/macrophages by regulating expression

\section{Figure 5}

Cytokine production by splenocytes stimulated to differentiate toward either Th1 or Th2 cells. Spleen cells were stimulated as described in Figure 4 legend, but with the addition of a cytokine or antibody that enhances Th1 or Th2 differentiation. (a) Exogenous IL-12 $(50 \mu \mathrm{g} / \mathrm{ml})$ was added to induce Th1 cell differentiation. (b) Anti-IL-12 $(100 \mu \mathrm{g} / \mathrm{ml})$ was added to induce Th2 cell differentiation. Conditioned media were analyzed for cytokine content by ELISA. The results represent the mean \pm SD of three experiments performed on triplicate wells using cells from three KO and three WT mice.

\section{Figure 4}

Cytokine production by splenocytes from VDR KO and WT mice. Mononuclear cells $\left(10^{6}\right.$ cells $\left./ \mathrm{ml}\right)$ from murine spleens were stimulated with $10 \mu \mathrm{g} / \mathrm{ml}$ anti-CD3 and $2 \mu \mathrm{g} / \mathrm{ml}$ anti-CD28. (a) Conditioned media were analyzed for cytokine content by ELISA. The results represent the mean \pm SD of experiments performed on triplicate wells using cells from three KO and three WT mice. (b) Cells were stimulated for the number of days indicated, and expression of IFN- $\gamma$ and $18 \mathrm{~S}$ was analyzed by RT-PCR.

of genes, including p21 Waf1/Cipl and c-jun $(29,36,37)$. This regulation can occur directly, via interaction of VDR with the promoter regions of target genes (35). For example, p21 Waf1/Cipl has a vitamin D response element in its promoter that responds to activated VDR and transactivates the gene $(29,36)$. Studies have shown that the c-jun terminal kinase (JNK) pathway is upregulated during monocyte/macrophage differentiation $(38,39)$. The results presented here demonstrate that $1,25(\mathrm{OH})_{2} \mathrm{D}_{3}$-activated intracellular signaling pathways require the presence of VDR to stimulate monocyte/macrophage differentiation. The signaling pathways for macrophage differentiation activated by TPA do not require VDR. Therefore, by comparing the regulation of different intracellular pathways in myeloid progenitor cells from VDR KO mice in response to $1,25(\mathrm{OH})_{2} \mathrm{D}_{3}$ or TPA, it may be possible to determine which pathways are used by the two agents.

Thus, the paradox is that the bone marrow cellularity, the absolute peripheral blood white cell count, and the percentage of monocytes/macrophages in the marrow and blood in the VDR KO and WT mice in our study were identical. This parallels the findings from
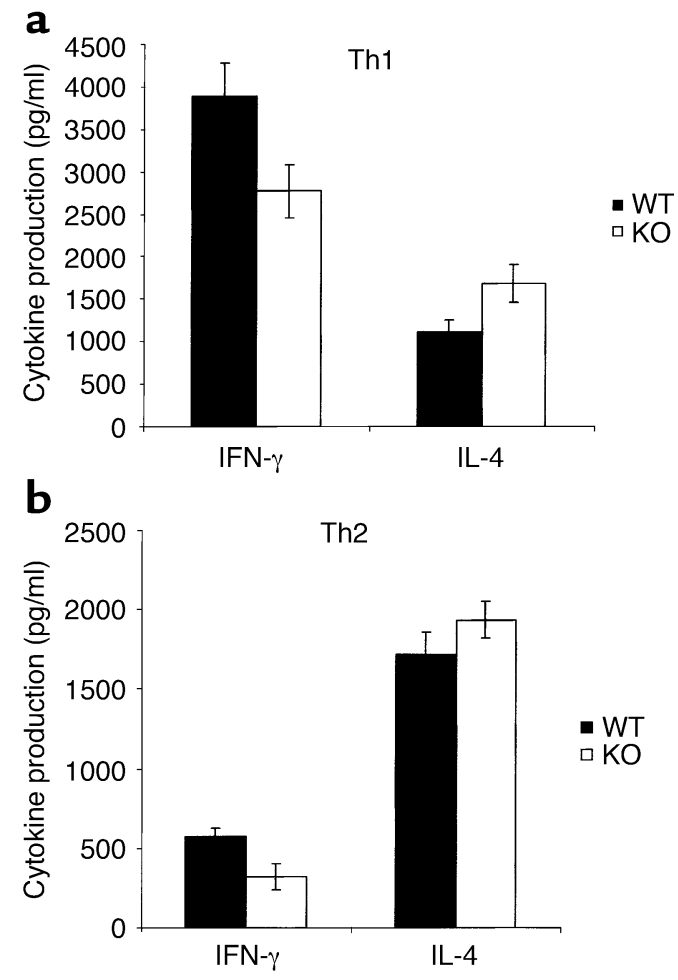

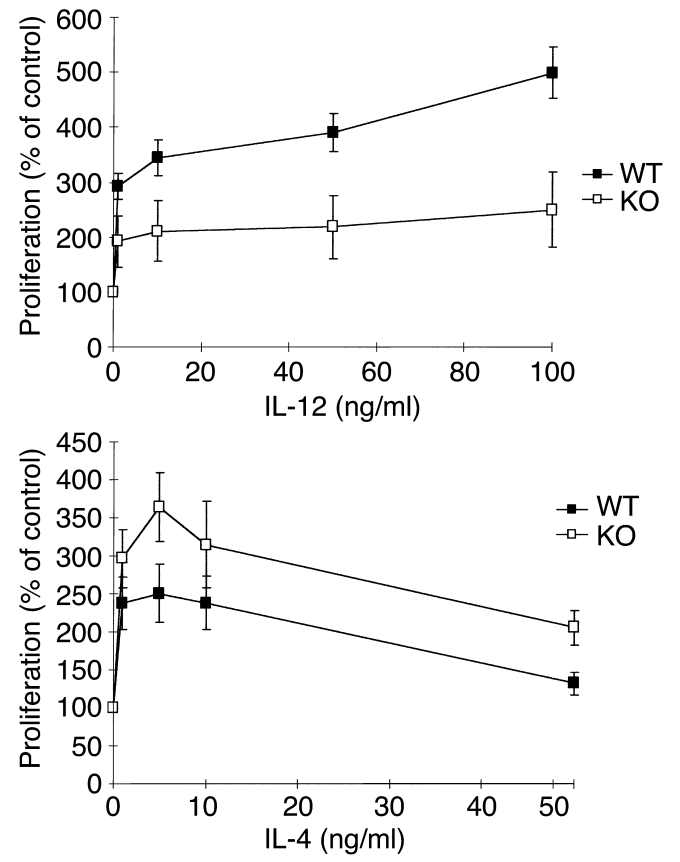

patients with vitamin D-dependent rickets type II, a disease associated with germline mutations of the VDR gene that either partially or completely inactivate the function of VDR. Their hematopoiesis, as reflected by their peripheral blood counts, bone marrow morphology, and myeloid colony formation, appear normal (27). These observations indicate that normal hematopoiesis, including development of monocytes/macrophages, does not require the nuclear VDR in vivo. Perhaps other mechanisms assure normal differentiation along the monocytic pathway.

Differential screening of immediate-early-response genes induced by $1,25(\mathrm{OH})_{2} \mathrm{D}_{3}$ in the myelomonocytic cell line U937 has revealed that the cyclin-dependent kinase inhibitor $\mathrm{p} 21^{\text {Wafl/Cip } 1}$ is important in VDR-directed myeloid differentiation into monocytes/macrophages $(29,36)$. Forced overexpression of this gene enhanced the differentiation of U937 cells into monocytes/macrophages. Our finding of normal expression of $\mathrm{p} 21^{\text {Waf1/Cip } 1}$ protein in mature macrophages from VDR KO mice indicates that $\mathrm{p} 21^{\text {Waf1/Cip } 1}$ expression is controlled by a variety of transcriptional regulators during macrophage differentiation.

\section{Figure 7}

Activation of pathways involved in T cell activation and differentiation in spleen cells from VDR KO and WT mice. Spleen cells were stimulated with $10 \mu \mathrm{g} / \mathrm{ml}$ anti-CD3 and $2 \mu \mathrm{g} / \mathrm{ml}$ anti-CD28 for 3 days, with either $100 \mathrm{ng} / \mathrm{ml} \mathrm{IL-12}$ and $50 \mu \mathrm{g} / \mathrm{ml}$ anti-IL-4 or $10 \mathrm{ng} / \mathrm{ml} \mathrm{IL-} 4$ and $10 \mu \mathrm{g} / \mathrm{ml}$ anti-IL-12. Protein expression of STAT4, NFATc, and GAPDH was determined by Western blot analysis after 3 days of stimulation. Immunoprecipitation (IP) of protein lysates was performed with anti-fyn antibody, and protein A-precipitated product was probed with an antibody against tyrosine kinase to detect phosphorylation. Ethidium bromide gels show RT-PCR for GM-CSF, IL-2, and $18 \mathrm{~S}$ after stimulation for 1 day.

\section{Figure 6}

Splenocyte proliferation in response to cytokines. Spleen cells were stimulated with $10 \mu \mathrm{g} / \mathrm{ml}$ anti-CD3 and $2 \mu \mathrm{g} / \mathrm{ml}$ anti-CD28 and treated with various concentrations of either IL-12 or IL-4 for 3 days. Proliferation was determined by measuring $\left[{ }^{3} \mathrm{H}\right]$ thymidine uptake during the last 14 hours of culture. The results represent the mean \pm SD of three experiments performed on triplicate wells using cells from three $\mathrm{KO}$ and three WT mice.

Expression of VDR and retinoid $\mathrm{X}$ receptor is required for the $1,25(\mathrm{OH})_{2} \mathrm{D}_{3}$-mediated repression of transcription and production of IL-12 in macrophages (25). However, we found that the absence of VDR in murine macrophages did not affect their production of IL-12 in response to activation, suggesting that multiple regulatory elements affect its expression. IL-18 (also known as IFN- $\gamma$-inducing factor) is a novel cytokine produced by macrophages that has recently been shown to induce a Th1 immune response $(30,31,40)$. Interestingly, production of IL-18 was less in macrophages from VDR KO animals than in WT animals, and $1,25(\mathrm{OH})_{2} \mathrm{D}_{3}$ increased the IL-18 levels in WT macrophage cultures (data not shown). This is the first report demonstrating the regulation of IL-18 by VDR or its ligand, $1,25(\mathrm{OH})_{2} \mathrm{D}_{3}$, and may account for some of the observations from the spleen cell cultures.

Generation of a coordinated Th1 and Th2 immune response results from the resolution of conflicting signals received by activated Th cells (41). The relationship between the two cell types is antagonistic, as these cells produce cytokines that both enhance their own differentiation and inhibit the development of the opposing subtype. Inhibition of the Th1 cytokines IFN- $\gamma$ and IL-12 by $1,25(\mathrm{OH})_{2} \mathrm{D}_{3}$ contributes to its anti-inflammatory properties (21). Therefore, splenocyte cultures

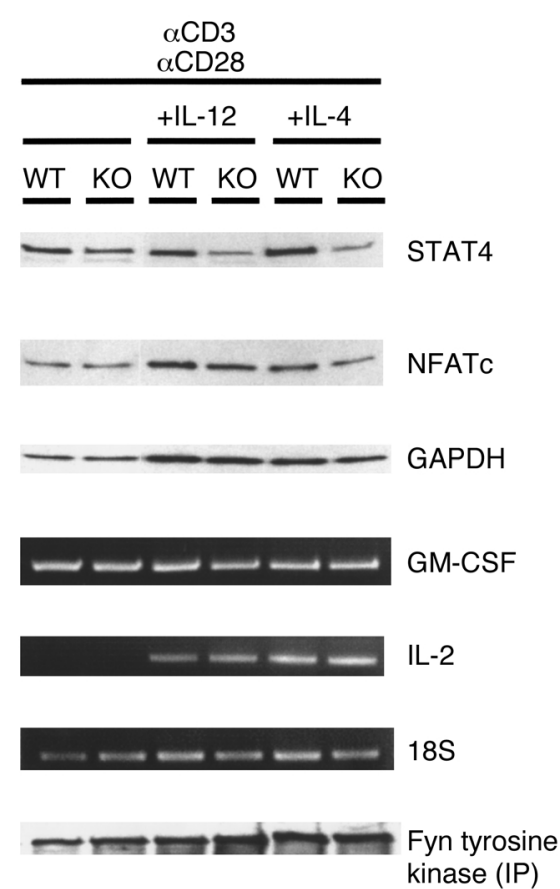


from VDR KO mice might be expected to be relieved of that repression and generate a greater Th1 response by producing more IFN- $\gamma$ and less IL-4. In fact, the opposite result was observed: less IFN- $\gamma$ and more IL- 4 was produced by murine VDR KO spleen cells than by WT spleen cells. This effect endured when either a cytokine or an antibody was added as a differentiation stimulus, suggesting that VDR is required to generate a normal Th1 immune response. The regulation of IFN- $\gamma$ did not occur at the transcriptional level, as shown in Figure $4 \mathrm{~b}$. Other cytokines produced by lymphocytes have been reported to regulate IFN- $\gamma$ by posttranscriptional mechanisms (42). Therefore, higher levels of Th2 cytokines produced by differentiating VDR KO spleen cells may act to suppress production of IFN- $\gamma$. Examination of transcription factors involved in Th cell differentiation revealed that protein levels of STAT4 were reduced in activated spleen cells from VDR KO mice compared with those from WT mice. Activation of STAT4 occurs after $T$ cell stimulation in the presence of IL-12 and is required for Th1 cell differentiation (43, 44). Additionally, T cells from STAT4 KO mice have been demonstrated to have a reduced ability to mount a Th1 immune response (45). Our results suggest that the reduced amounts of IFN- $\gamma$ produced by Th 1 cells from VDR KO mice are due to their lower levels of STAT4 expression.

Among cytokines directly repressed by $1,25(\mathrm{OH})_{2} \mathrm{D}_{3}$, IL-2 and GM-CSF have been shown to have their expression inhibited by blockade of NFATc-driven transcription (46-48). When we examined NFATc protein levels, no differences were detected between splenocytes from WT and KO mice. However, the presence of VDR:retinoid X receptor heterodimers has been shown to block binding of NFATc to the promoter regions of its target genes (46-48), so a lack of change in protein expression may not fully reflect events occurring in the promoter regions of genes targeted by this transcription factor. Therefore, we examined mRNA levels of IL-2 and GM-CSF. We found no differences in expression between VDR KO and WT cells, suggesting that the absence of VDR does not affect NFATc signaling in activated splenocytes.

The decreased proliferation of VDR KO splenocytes compared with WT splenocytes in response to IL-12 would be expected to contribute to the lower levels of IFN- $\gamma$ and higher levels of IL- 4 seen in these cultures. The mechanisms behind the differences in proliferation in response to stimulation are unknown, but they do not appear to be due to defects in signaling by the $T$ cell receptor. This was demonstrated by the normal phosphorylation of the signaling molecule fyn, which had previously been shown to be activated in Th1 cell clones following anti-CD3 stimulation (49).

The weaker Th1 cell response we observed in the VDR $\mathrm{KO}$ murine splenocyte cultures is difficult to reconcile with the numerous studies showing that $1,25(\mathrm{OH})_{2} \mathrm{D}_{3}$ is able to suppress this pathway in vivo and in vitro. A study using oligonucleotide array analysis to compare gene expression profiles between Th1 and Th2 cells showed that levels of VDR were elevated in Th1 cells when they were treated with IL-12, in a pattern similar to that of known Th1-specific genes (50). In this context, the data suggest that expression of the VDR itself may be important in Th1 cell development. In support of this concept, one study in which U937 cells were transfected with cadmium-inducible antisense VDR showed increased levels of apoptosis and a decreased proportion of cells in the cell cycle when VDR was inhibited (51). This pattern appears to also occur in Th1 cells, where in the absence of VDR, exogenous IL-12 is unable to induce normal levels of splenic cell proliferation.

The reduced ability of VDR KO macrophages to produce IL-18 may contribute to the weaker Th1 response by the activated splenocytes. IL- 18 has been shown to directly enhance cytokine production by activated Th1 cells, an effect partially dependent on IL-2, but independent of IL-12 $(30,31)$. In addition, spleens from IL-18-deficient mice infected with either Mycobacterium tuberculosis or Mycobacterium bovis BCG Pasteur produced less IFN- $\gamma$ than WT mice did (52). Therefore, IL-18 synthesized by splenic macrophages may be important in the generation of cytokines by Th1 cells. In our experiments, insufficient IL-18 secretion by macrophages appears to contribute to reduced IFN- $\gamma$ production by VDR KO splenocyte cultures, which leads to greater production of IL-4 by Th2 cells.

In summary, we have demonstrated that VDR is absolutely required for $1,25(\mathrm{OH})_{2} \mathrm{D}_{3}$ to induce the differentiation of bone marrow progenitors into monocytes/macrophages, but monocyte/macrophage differentiation can occur in the absence of VDR. Expression of VDR was shown to be important for the generation of a Th1-type immune response by spleen cells. Our results suggest that fewer Th1 cells are generated in the absence of VDR in response to antibody stimulation, and that VDR regulation of IL-18 production by macrophages, and STAT4 expression by activated splenocytes may be involved in this process.

\section{Acknowledgments}

This work was supported by grants from NIH, the Department of Defense, the Lymphoma Foundation of America, LEO Pharmaceutical Products, and the Ko-So Foundation. H.P. Koeffler holds the Mark Goodson Chair in Oncology Research and is a member of the Jonsson Cancer Center.

\footnotetext{
1. Mangelsdorf, D.J., et al. 1995. The nuclear receptor superfamily: the second decade. Cell. 83:835-839.

2. Christakos, S., Raval-Pandya, M., Wernyj, R.P., and Yang, W. 1996. Genomic mechanisms involved in the pleiotropic actions of 1,25-dihydroxyvitamin $\mathrm{D}_{3}$. Biochem. J. 316:361-371.

3. Reichel, H., Koeffler, H.P., and Norman, A.W. 1989. The role of the vitamin D endocrine system in health and disease. N. Engl. J. Med. 320:980-991.

4. Yoshizawa, T., et al. 1997. Mice lacking the vitamin D receptor exhibit impaired bone formation, uterine hypoplasia and growth retardation after weaning. Nat. Genet. 16:391-396.

5. Kinuta, K., et al. 2000. Vitamin D is an important factor in estrogen biosynthesis of both male and female gonads. Endocrinology. 141:1317-1324.
} 
6. Li, Y.C., et al. 1997. Targeted ablation of the vitamin D receptor: an animal model of vitamin D-dependent rickets type II with alopecia. Proc. Natl. Acad. Sci. USA. 94:9831-9835.

7. Sakai, Y., and Demay, M.B. 2000. Evaluation of keratinocyte proliferation and differentiation in vitamin $\mathrm{D}$ receptor knockout mice. Endocrinology. 141:2043-2049.

8. Kizaki, M., et al. 1991. 1,25-dihydroxyvitamin D3 receptor RNA: expression in hematopoietic cells. Blood. 77:1238-1247.

9. Provvedini, D.M., Tsoukas, C.D., Deftos, L.J., and Manolagas, S.C. 1983. 1,25-dihydroxyvitamin D3 receptors in human leukocytes. Science. 221:1181-1183.

10. Koeffler, H.P., Amatruda, T., Ikekawa, N., Kobayashi, Y., and Deluca, H. 1984. Induction of macrophage differentiation of normal and leukemic myeloid stem cells by 1,25-dihydroxyvitamin $\mathrm{D}_{3}$ and its fluorinated analogues. Cancer Res. 44:5624-5628.

11. McCarthy, D.M., et al. 1983. 1,25-dihydroxyvitamin $\mathrm{D}_{3}$ inhibits proliferation of human promyelocytic leukaemia (HL60) cells and induces monocyte-macrophage differentiation in HL60 and normal human bone marrow cells. Leuk. Res. 7:51-55.

12. Nagler, A., Ricklis, I., Ketter, Y., Tatatsky, I., and Fabian, I. 1986. Effect of 1,25-dihydroxyvitamin D3 and retinoic acid on normal and pluripotent (CFU-mix), erythroid (BFU-E) and myeloid (CFU-C) progenitor cell growth and differentiation patterns. Exp. Hematol. 14:60-65.

13. Munker, R., Norman, A., and Koeffler, H.P. 1986. Vitamin D compounds: effect on clonal proliferation and differentiation of human myeloid cells. J. Clin. Invest. 78:424-430.

14. Abe, E., et al. 1981. Differentiation of mouse myeloid leukemia cells induced by $1 \alpha, 25$-dihydroxyvitamin $\mathrm{D}_{3}$. Proc. Natl. Acad. Sci. USA 78:4990-4994

15. Koeffler, H.P., Reichel, H., Bishop, J.E., and Norman, A.W. 1985. Gammainterferon stimulates production of 1,25-dihydroxyvitamin $\mathrm{D}_{3}$ by normal macrophages. Biochem. Biophys. Res. Comm. 127:596-603.

16. Adams, J.S., and Gacad, M.A. 1985. Characterisation of $1 \alpha$-hydroxylation of vitamin $\mathrm{D}_{3}$ sterols by cultured alveolar macrophages from patients with sarcoidosis. J. Exp. Med. 161:755-765.

17. Rigby, W.F.C., Stacy, T., and Fanger, M.W. 1984. Inhibition of T lymphocyte mitogenesis by 1,25 -dihydroxyvitamin D3 (calcitriol). J. Clin. Invest. 74:1451-1455.

18. Tobler, A., Gasson, H., Reichel, H., Norman, A.W., and Koeffler, H.P. 1987. Granulocyte-macrophage colony stimulating factor: sensitive and receptor-mediated regulation by 1,25 -dihydroxyvitamin $\mathrm{D}_{3}$ in normal human peripheral blood lymphocytes. J. Clin. Invest. 79:1700-1705.

19. Reichel, H., Koeffler, H.P., Tobler, A., and Norman, A.W. 1987. 1 $\alpha, 25$ dihydroxyvitamin D3 inhibits $\gamma$-interferon synthesis by normal human peripheral blood lymphocytes. Proc. Natl. Acad. Sci. USA. 84:3385-3389.

20. Tsoukas, C.D., Provvedini, D.M., and Manolagas, S.C. 1984. 1,25-dihydroxyvitamin D3: a novel immunoregulatory hormone. Science. 224:1438-1440.

21. Lemire, J.M., Archer, D.C., Beck, L., and Spiegelberg, H.L. 1995. Immunosuppressive actions of 1,25-dihydroxyvitamin D3: preferential inhibition of Th1 functions. J. Nutr. 125:1704S-1708S

22. Lemire, J.M., et al. 1985. 1,25-dihydroxyvitamin D3 suppresses human $\mathrm{T}$ helper/inducer lymphocyte activity in vitro. J. Immunol. 134:3032-3035.

23. Mosmann, T.R., Cherwinski, H.M., Bond, M.W., Giedlin, M.A., and Coffman, R.L. 1986. Two types of murine helper T cell clone. I. Definition according to profiles of lymphokine activities and secreted proteins. J. Immunol. 136:2348-2357.

24. Paul, W.E., and Seder, R.A. 1994. Lymphocyte responses and cytokines. Cell. 76:241-251

25. D'Ambrosio, D., et al. 1998. Inhibition of IL-12 production by 1,25-dihydroxyvitamin D3. Involvement of NF- $\kappa \mathrm{B}$ downregulation in transcriptional repression of the $\mathrm{p} 40$ gene. J. Clin. Invest. 101:252-262.

26. Koeffler, H.P., et al. 1990. Lymphocyte cell lines from vitamin D-dependent rickets type II show functional defects in the $1 \alpha, 25$-dihydroxyvita$\min \mathrm{D}_{3}$ receptor. Mol. Cell. Endocrinol. 70:1-11.

27. Nagler, A., et al. 1987. Myeloid progenitors from the bone marrow of patients with vitamin D resistant rickets (type II) fail to respond to $1,25(\mathrm{OH})_{2} \mathrm{D}_{3}$. Brit. J. Haematol. 67:267-271.

28. Koeffler, H.P. 1981. Human myelogenous leukemia: enhanced clonal proliferation in the presence of phorbol diesters. Blood. 57:256-260.

29. Liu, M., Lee, M.-H., Cohen, M., Bommakanti, M., and Freedman, L.P. 1996. Transcriptional activation of the Cdk inhibitor $\mathrm{p} 21$ by vitamin $D_{3}$ leads to the induced differentiation of the myelomonocytic cell line U937. Genes Dev. 10:142-153.

30. Okamura, H., et al. 1995. Cloning of a new cytokine that induces IFNgamma production by T cells. Nature. 378:88-90.

31. Micallef, M.J., et al. 1996. Interferon-gamma-inducing factor enhances T helper 1 cytokine production by stimulated human T cells: synergism with interleukin-12 for interferon-gamma production. Eur. J. Immunol. 26:1647-1651.

32. Tamura, T., et al. 1995. Early activation signal transduction pathways of Th1 and Th2 cell clones stimulated with anti-CD3. Roles of protein tyrosine kinases in the signal for IL-2 and IL-4 production. J. Immunol. 155:4692-4701.

33. Morosetti, R., and Koeffler, H.P. 1997. Vitamin D compounds and analogues: effects on normal and abnormal hematopoiesis. In: Vitamin D. D. Feldman, F.H. Glorieux, and J.W. Pike, editors. Academic Press. San Diego, California, USA. 1155-1166.

34. Bunce, C.M., Brown, G., and Hewison, M. 1997. Vitamin D and hematopoiesis. Trends Endocrinol. Metab. 8:245-251.

35. Hannah, S.S., and Norman, A.W. 1994. $1 \alpha, 25(\mathrm{OH})_{2}$-vitamin $\mathrm{D}_{3}$-regulated expression of the eukaryotic genome. Nutr. Rev. 52:376-382.

36. Rots, N.Y., Lui, M., Anderson, E.C., and Freedman, L.P. 1998. A differential screen for ligand-regulated genes: identification of HoxA10 as a target of vitamin $\mathrm{D}_{3}$ induction in myeloid leukemic cells. Mol. Cell. Biol. 18:1911-1918.

37. Gaynor, R., Simon, K., and Koeffler, H.P. 1991. Expression of c-jun during macrophage differentiation of HL-60 cells. Blood. 15:2618-2623.

38. Wang X., Rao, J., and Studzinski, G.P. 2000. Inhibition of p38 MAP kinase activity up-regulates multiple MAP kinase pathways and potentiates 1,25-dihydroxyvitamin $\mathrm{D}(3)$-induced differentiation of human leukemia HL-60 cells. Exp. Cell Res. 258:425-437.

39. Wang, X., and Studzinski, G.P. 2001. Inhibition of p38 MAP kinase potentiates the JNK/SAPK pathway and AP-1 activity in monocytic but not in macrophage or granulocytic differentiation of HL-60 cells. J. Cell. Biochem. 82:68-77.

40. Akira, S. 2000. The role of IL-18 in innate immunity. Curr. Opin. Immunol. 12:59-63

41. Begley, C.G., and Nicola, N.A. 1999. Resolving conflicting signals: cross inhibition of cytokine signaling pathways. Blood. 93:1443-1447.

42. Borger, P., Kauffman, H.F., Postma, D.S., and Vellenga, E. 1996. IL-7 differentially modulates the expression of IFN-gamma and IL-4 in activated human $\mathrm{T}$ lymphocytes by transcriptional and post-transcriptional mechanisms. J. Immunol. 156:1333-1338.

43. Bacon, C.M., et al. 1995. Interleukin 12 induces tyrosine phosphorylation and activation of STAT4 in human lymphocytes. Proc. Natl. Acad. Sci. USA. 92:7307-7311.

44. Jacobson, N.G., et al. 1995. Interleukin 12 signaling in T helper type 1 (Th1) cells involves tyrosine phosphorylation of signal transducer and activator of transcription (Stat) 3 and Stat4. J. Exp. Med. 181:1755-1762.

45. Kaplan, M.H., Sun, Y.L., Hoey, T., and Grusby, M.J. 1996. Impaired IL-12 responses and enhanced development of Th2 cells in Stat4-deficient mice. Nature. 382:171-174.

46. Towers, T., Staeva, T., and Freedman, L.P. 1999. A two-hit mechanism for vitamin $\mathrm{D}_{3}$-mediated transcriptional repression of the granulocytemacrophage colony-stimulating factor gene: vitamin D receptor competes for DNA binding with NFAT1 and stabilizes c-Jun. Mol. Cell. Biol. 19:4191-4199.

47. Alroy, I., Towers, T., and Freedman, L.P. 1995. Transcriptional repression of the interleukin-2 gene by vitamin $\mathrm{D}_{3}$ : direct inhibition of NFATp/AP-1 complex formation by a nuclear hormone receptor. Mol. Cell. Biol. 15:5789-5799.

48. Takeuchi, A., et al. 1998. Nuclear factor of activated T cells (NFAT) as a molecular target for $1 \alpha, 25$-dihydroxyvitamin $\mathrm{D}_{3}$-mediated effects. J. Immunol. 160:209-218.

49. Tamura, T., et al. 1995. Early activation signal transduction pathways of Th1 and Th 2 cell clones stimulated with anti-CD3. Roles of protein tyrosine kinases in the signal for IL-2 and IL-4 production. J. Immunol. 155:4692-4701.

50. Rogge, L., et al. 2000. Transcript imaging of the development of human T helper cells using oligonucleotide arrays. Nat. Genet. 25:96-101.

51. Hewison, M., et al. 1996. Antisense inhibition of vitamin D receptor expression induces apoptosis in monoblastoid U937 cells. J. Immunol. 156:4391-4400

52. Sugawara, I., et al. 1999. Role of interleukin-18 (IL-18) in mycobacterial infection in IL-18-gene-disrupted mice. Infect. Immunol. 67:2585-2589. 